\title{
Notes on the vocalizations of Midget Flowerpecker (Dicaeum aeneum)
}

\section{Peter Boesman}

In the following we briefly analyze and compare voice of the three races of Midget Flowerpecker (Dicaeum aeneum). We also try to quantify the extent of any vocal differences using the criteria proposed by Tobias et al. (2010), as a support for taxonomic review.

We have made use of sound recordings available on-line from Xeno Canto (XC) and Macaulay Library (ML).

An overview of vocalizations:

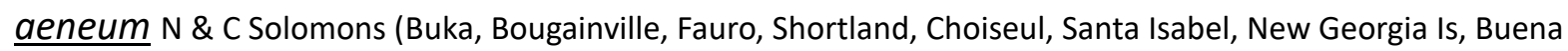
Vista, Florida Is).

High-pitched buzzy call

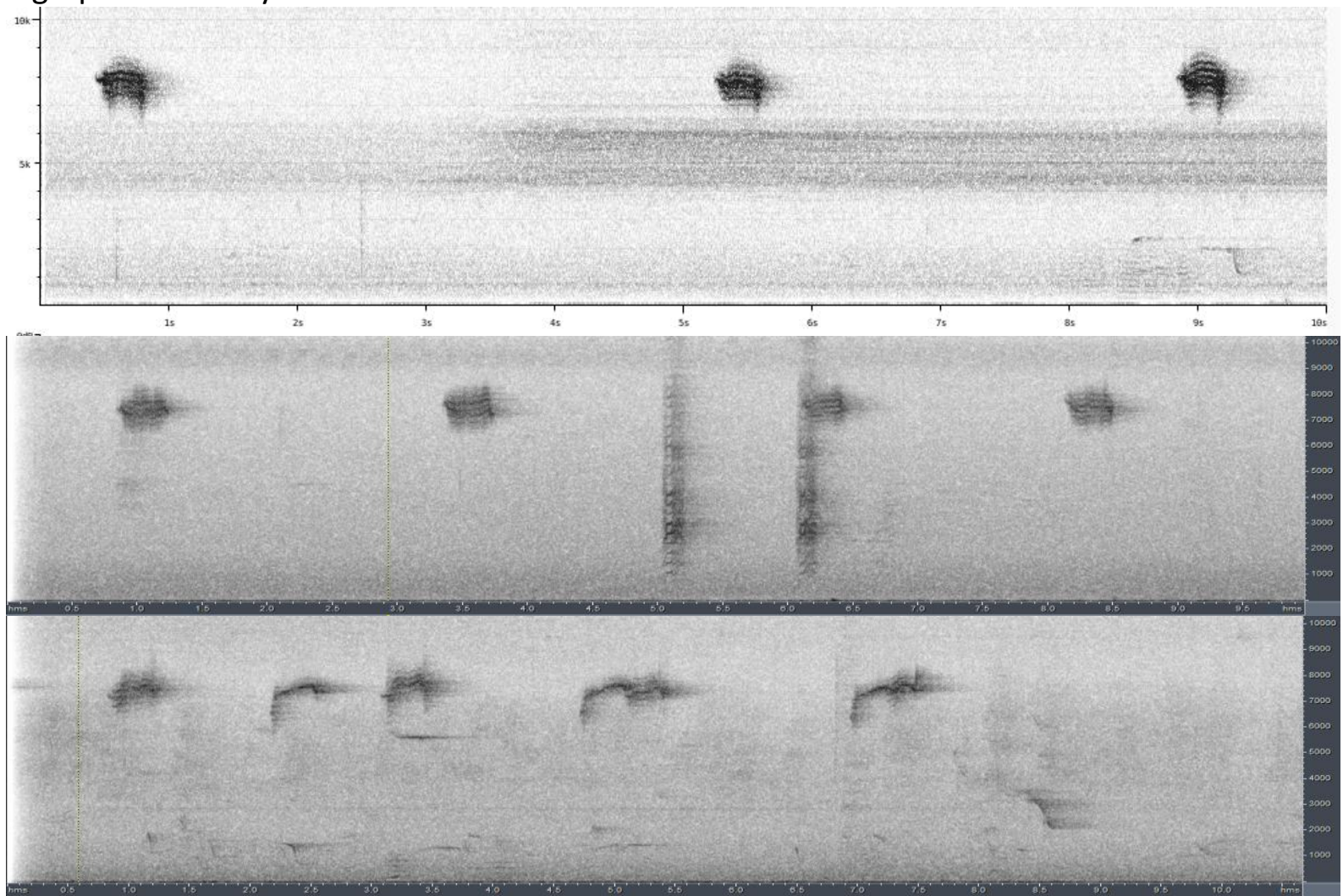

High-pitched "tsee" call

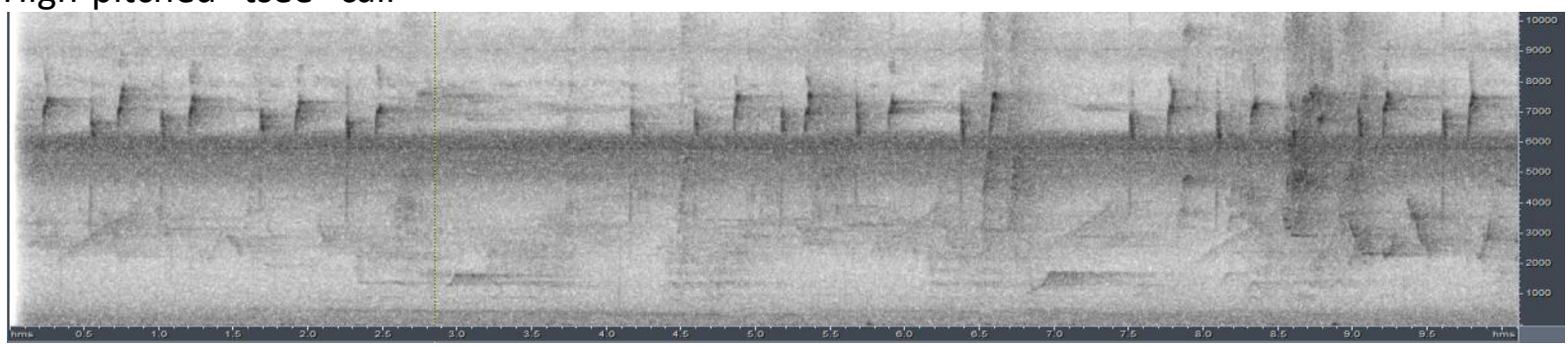




\section{HANDBOOK OF THE \\ BIRDSPF TUE WORLD}

\section{ORNITHOLOGICAL NOTES}

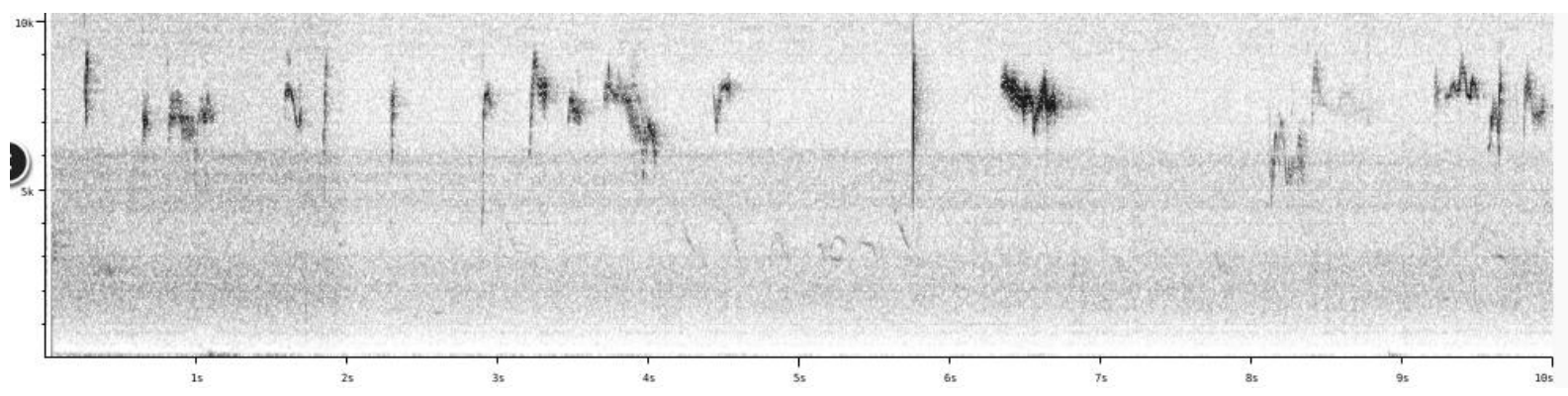

Hard "chick" call

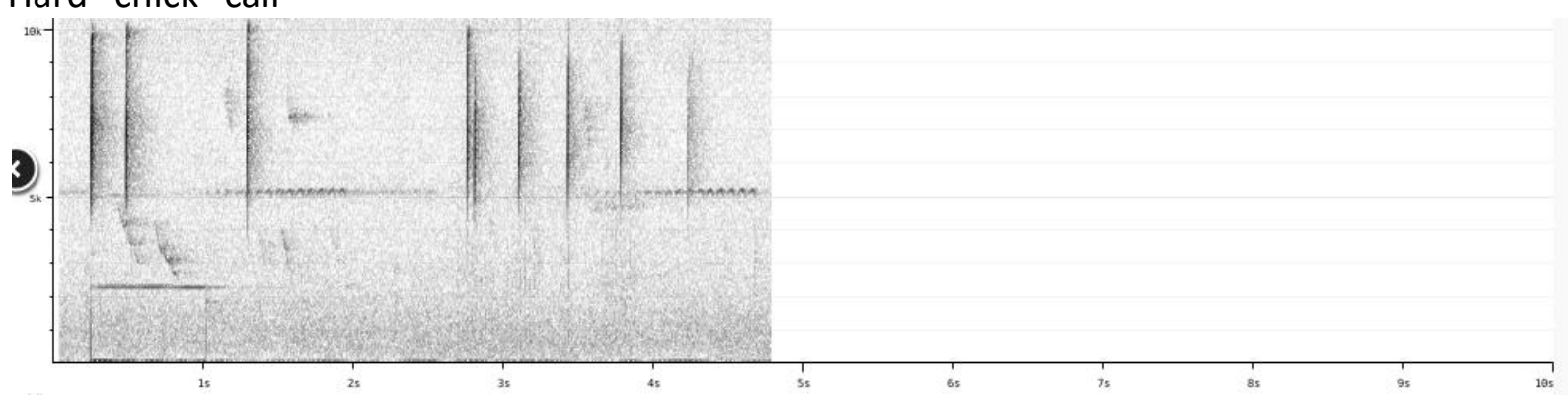

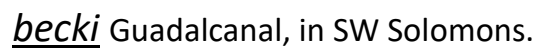

High-pitched buzzy call
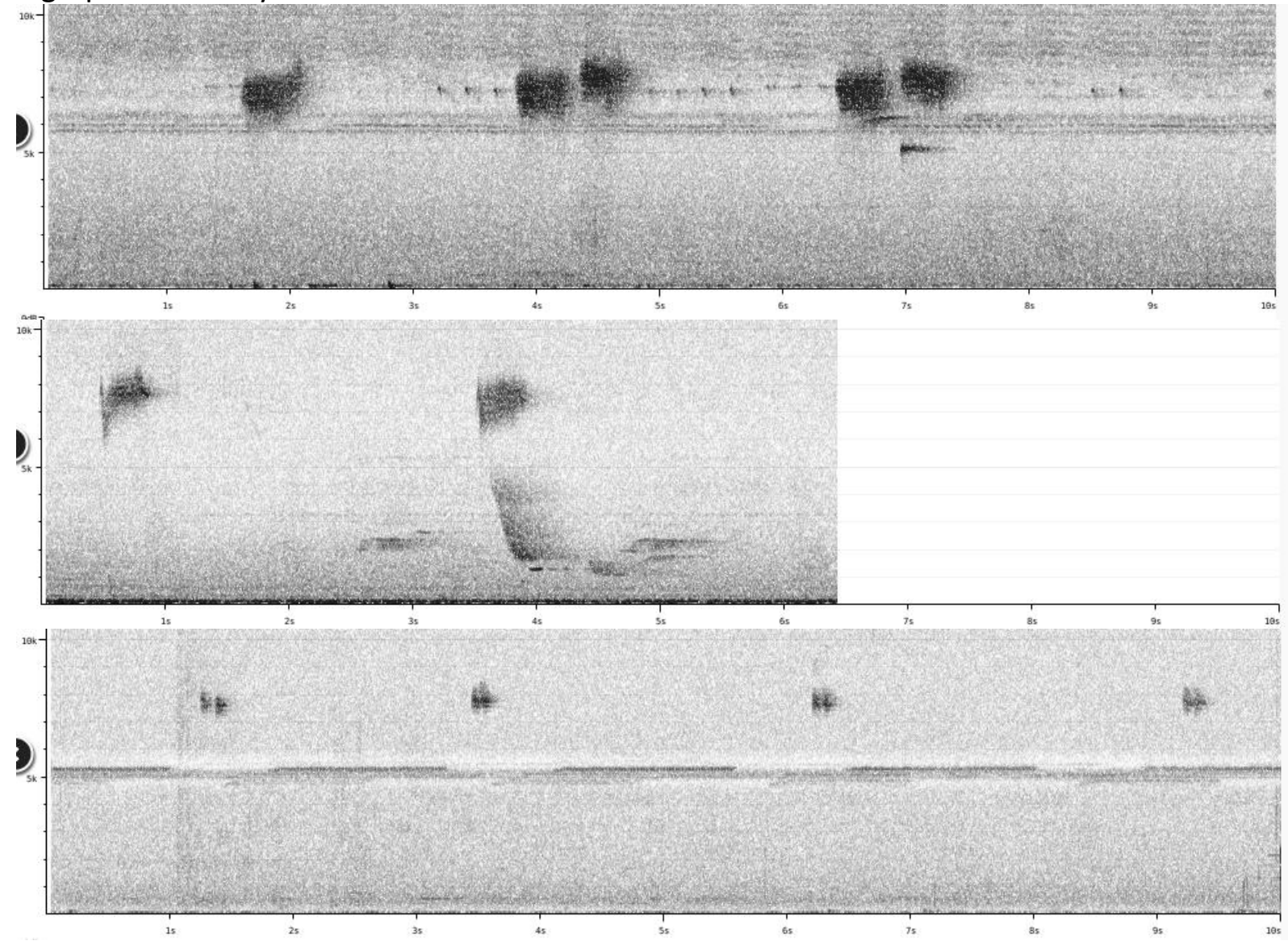

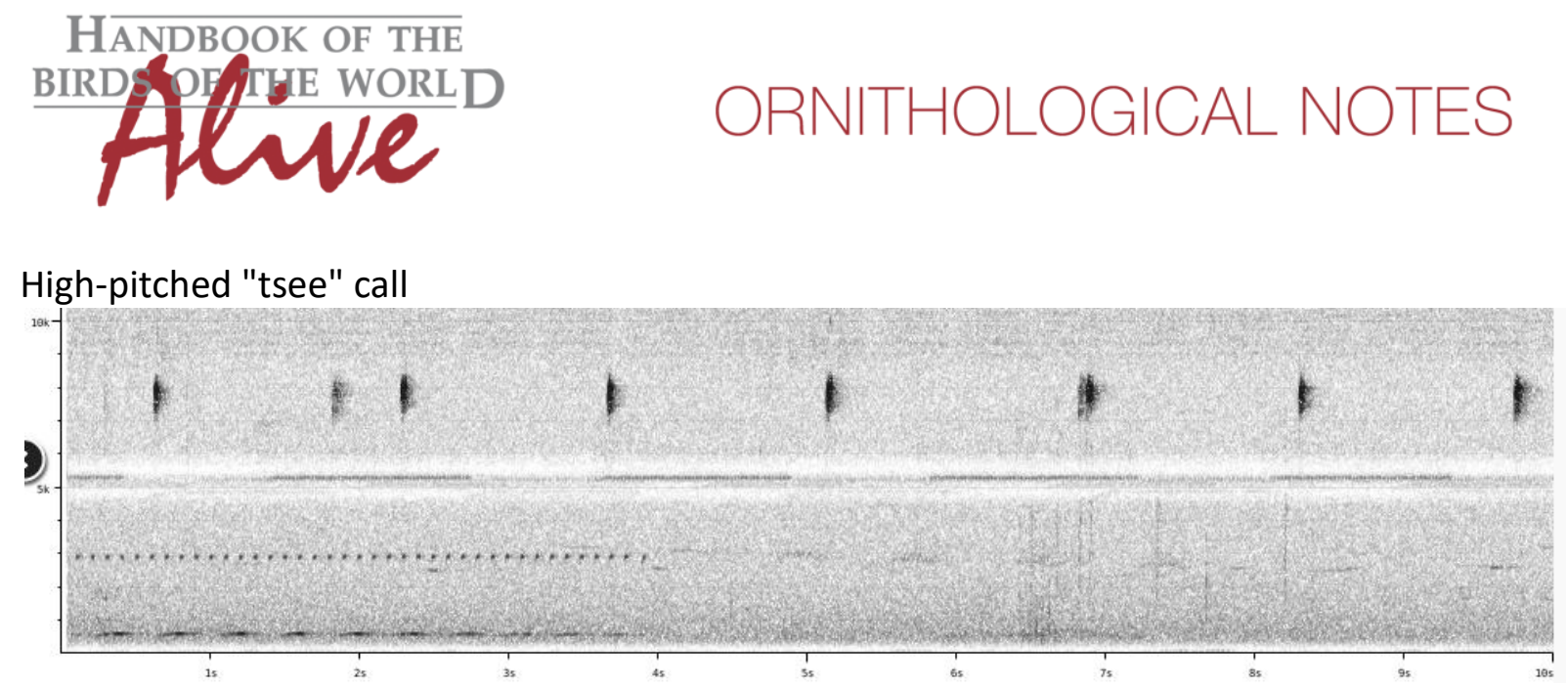

Hard "chick" call

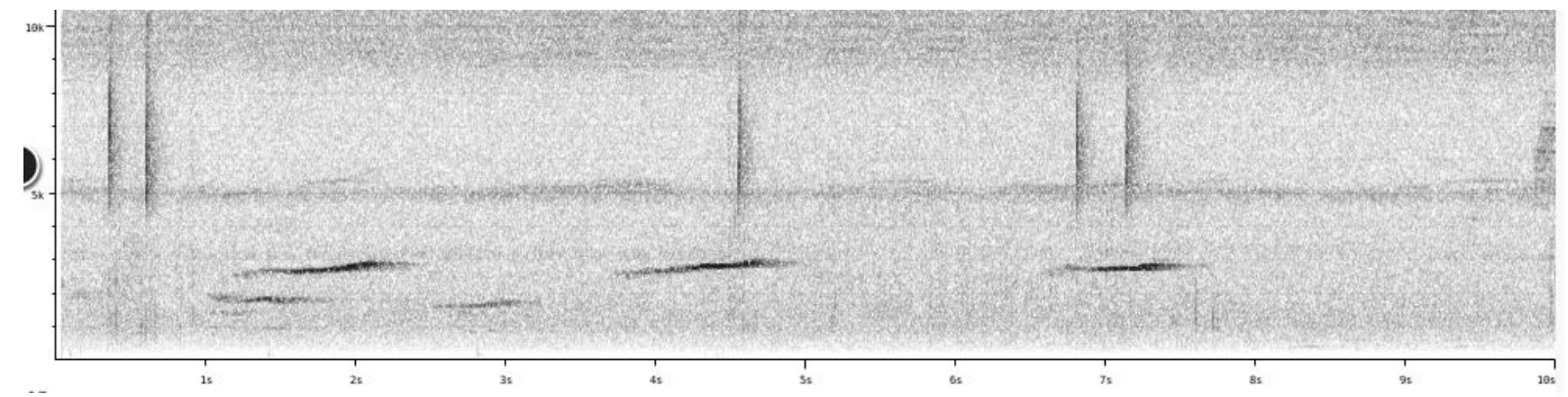

$\underline{\text { malaitae }}$ Malaita I, in E Solomons.

No recordings available.

aeneum and becki share both the high-pitched buzzy call, a high-pitched "tsee" call and a hard 'chek' call. With only a few recordings of other call types, it is only guessing if these are unique to one of the taxa. Based on the available recordings, we can only conclude there are no obvious vocal differences.

Voice of malaitae remains unknown (?), for which we can't draw any conclusions.

This note was finalized on 25th April 2016, using sound recordings available on-line at that moment. We would like to thank in particular the sound recordists who placed their recordings for this species on XC and ML: Niels Krabbe, Frank Lambert, Mark Robbins and Mark Todd.

\section{References}

Tobias, J.A., Seddon, N., Spottiswoode, C.N., Pilgrim, J.D., Fishpool, L.D.C. \& Collar, N.J. (2010). Quantitative criteria for species delimitation. Ibis 152(4): 724-746.

\section{Recommended citation}

Boesman, P. (2016). Notes on the vocalizations of Midget Flowerpecker (Dicaeum aeneum). HBW Alive Ornithological Note 336. In: Handbook of the Birds of the World Alive. Lynx Edicions, Barcelona. (retrieved from http://www.hbw.com/node/1252795 on 25 October 2016). 